\title{
Diagnosis and management of acute esophageal necrosis
}

\author{
Emanuel Dias, João Santos-Antunes, Guilherme Macedo
}

Centro Hospitalar de São João, Porto, Portugal

\begin{abstract}
Acute esophageal necrosis is a rare syndrome classically characterized by a striking endoscopic image of diffuse and circumferential black mucosal discoloration of distal esophagus, with an abrupt transition at the gastroesophageal junction and variable proximal extension. The typical patient is an older male with general debilitation and multiple comorbidities presenting with hematemesis or melena. The pathophysiology usually involves a combination of esophageal ischemia, backflow injury from gastric chemical contents and impaired mucosal reparative mechanisms associated with debilitated physical states. It may arise in the setting of hemodynamic compromise, diabetic ketoacidosis, hypothermia, alcoholic intoxication, trauma, inflammatory diseases, esophageal local infection, solid organ transplantation, postoperative status, drugs or acute gastric outlet obstruction, usually in the background of a chronic debilitating process, where the concurrent presence of multiple risk factors, including diabetes mellitus, hypertension, malnutrition, malignancy or alcohol abuse, places a patient at higher risk. The characteristic endoscopic appearance establishes the diagnosis. Biopsy is supportive but not required. Management is mainly supportive and consists of correcting coexisting conditions, fluid therapy, bowel rest, intravenous proton pump inhibitor therapy and red blood cell transfusion as needed. Although this is a serious life-threatening condition, appropriate treatment may result in a favorable outcome in the majority of patients.
\end{abstract}

Keywords Acute esophageal necrosis, black esophagus, acute necrotizing esophagitis, gastrointestinal bleeding

Ann Gastroenterol 2019; 32 (6): 1-12

\section{Introduction}

Acute esophageal necrosis (AEN), also known as black esophagus or acute necrotizing esophagitis, is a rare cause of upper gastrointestinal bleeding (UGB), first described in 1990 by Goldenberg et al [1] and later classified as a distinct syndrome by Gurvits et al [2,3], with an incidence of 0.01 $0.28 \%$ of patients undergoing esophagogastroduodenoscopy (EGD) $[4,5]$. It is defined endoscopically by a circumferential black-appearing esophageal mucosa with nearly universal involvement of the distal esophagus and abrupt transition at the gastroesophageal junction, with variable proximal extension. The mechanism of damage is usually multifactorial and secondary to a combination of ischemic compromise, acute

Gastroenterology Department, Faculty of Medicine, Centro Hospitalar de São João, Porto, Portugal

\section{Conflict of Interest: None}

Correspondence to: Emanuel Dias, Gastroenterology Department, Centro Hospitalar de São João, Alameda Professor Hernâni Monteiro, 4200-319, Porto, Portugal, e-mail: diasj0310@gmail.com

Received 21 May 2019; accepted 26 July 2019; published online 26 September 2019

DOI: https://doi.org/10.20524/aog.2019.0418 gastric outlet obstruction and malnutrition [2]. A high index of suspicion is key in the diagnosis, particularly in older patients with multiple comorbidities who present with UGB. In fact, its true prevalence may be underestimated and greater awareness of this disease significantly increases its detection rate [6].

Although this disease has been previously described by Gurvits et al [2,3], important information concerning its etiology and management has been provided in subsequent case reports and small case series. Therefore, this article aims to provide an updated and comprehensive review of the pathophysiology, etiology, diagnosis and management of AEN.

\section{Epidemiology}

$\mathrm{AEN}$ is a rare clinical entity with an incidence of $0.01-0.28 \%$ of patients undergoing EGD, according to retrospective [4-8] and prospective studies [9], summarized in Table 1. In these studies, the diagnosis of AEN was based on similar clinical and endoscopic criteria: acute presentation of hematemesis or melena; endoscopic finding of black-appearing esophageal mucosa, more accentuated in the lower third and terminating abruptly at the gastroesophageal junction (GEJ); and exclusion of other causes of esophageal injury, including caustic ingestion, infections, trauma and radiotherapy, based on clinical history 
Table 1 Main characteristics of retrospective and prospective studies regarding the incidence of acute esophageal necrosis

\begin{tabular}{lllcccc}
\hline Authors & Year & $\begin{array}{l}\text { Type of } \\
\text { study }\end{array}$ & $\begin{array}{c}\text { Duration } \\
\text { (years) }\end{array}$ & $\begin{array}{c}\text { Number of } \\
\text { EGD examined }\end{array}$ & $\begin{array}{c}\text { Total cases } \\
\text { of AEN }\end{array}$ & $\begin{array}{c}\text { Incidence } \\
\text { of AEN }\end{array}$ \\
\hline Moreto et al [4] & 1993 & Retrospective & 16 & 80.000 & 16 & $0.01 \%$ \\
Augusto et al [5] & 2004 & Retrospective & 5 & 10.295 & 6003 & 29 \\
\hline Julian-Gomez et al [6] & 2008 & Retrospective & 2 & 3976 & 7 & $0.28 \%$ \\
Ramos et al [7] & 2008 & Retrospective & 2 & 9179 & 5 & $0.28 \%$ \\
\hline Singh et al [8] & 2011 & Retrospective & 3 & 3900 & $8.05 \%$ \\
\hline Ben Soussan et al [9] & 2002 & Prospective & 1 & $0.2 \%$ \\
\hline
\end{tabular}

EGD, esophagogastroduodenoscopy; AEN, acute esophageal necrosis

and endoscopic findings, complemented by biopsy when necessary. Based on these same criteria, a 3-year retrospective study reported a prevalence of approximately $6 \%$, considering only EGD performed in patients presenting to an emergency department with UGB [10]. This suggests that the incidence of this disease may be higher than generally believed, especially in patients presenting with active UGB. In fact, another retrospective study demonstrated that this could possibly be related to underdiagnosis and erroneous labeling of findings as reflux esophagitis, with greater awareness of this disease being associated with an increased detection rate [6].

Men are 4 times more commonly affected than women. Incidence increases with age and peaks in the seventh decade of life [3]. Patients usually present multiple comorbidities, the most common being diabetes mellitus (38\%), hypertension (37\%), alcohol abuse (25\%), chronic kidney disease (16\%), coronary heart disease (12\%), dyslipidemia (10\%), peripheral artery disease (10\%), malignancy (10\%), liver cirrhosis (9\%), gastroesophageal reflux disease (9\%), congestive heart failure (7\%), and chronic obstructive pulmonary disease (5\%) [11].

Therefore, although rare, this disease may be responsible for a significant proportion of episodes of UGB and should be particularly suspected in older males with general debilitation and multiple medical conditions who present with hemodynamic compromise and UGB.

\section{Pathophysiology}

The pathophysiology of AEN usually involves a combination of multiple mechanisms, including the esophageal ischemia usually seen in hemodynamic compromise and low-flow states, backflow injury from gastric acid, and impaired mucosal reparative mechanisms present in debilitated physical states [2].

\section{Esophageal ischemia}

Esophageal ischemia may be secondary to hemodynamic compromise in patients with risk factors for significant vasculopathy (male sex, advanced age, diabetes mellitus, hypertension or chronic kidney disease, among others), who are therefore more predisposed to ischemic events. In such patients, hypotension may result in esophageal hypoperfusion and ischemic necrosis [2].

The role of ischemia is supported by the observation that this disease may occur in combination with other ischemic events that affect the splanchnic circulation, such as ischemic cholangiopathy [12] or hypoxic hepatitis [13], which also result from generalized states of hypoperfusion in patients with similar risk factors for advanced atherosclerosis. Accordingly, the low incidence of this disease compared with other ischemic events (for example, acute coronary syndrome) among susceptible patients could be related to the complex anastomotic vascular network present in the esophageal submucosa. The predilection for distal esophagus could be related to its lower degree of vascularization compared to the proximal and middle portions [14]. Nevertheless, AEN may also occur in the absence of shock or hypotension [15], which suggests that, despite being associated with increased risk, hemodynamic compromise is not per se an essential condition for the development of AEN.

\section{General debilitation}

There is a clear predilection for AEN to occur in patients who present with a poor nutritional status and general debilitation that compromises local protective barriers and impairs mucosal regenerative capacity. This is usually related to the presence of multiple chronic comorbidities, including malignancy, alcohol abuse, cirrhosis, chronic kidney disease, congestive heart failure, chronic pulmonary disease, and postoperative status [3]. However, AEN may also occur in otherwise healthy, young patients with no other comorbidities [16], which suggests that some events may precipitate the disease even in the absence of a state of general debilitation.

\section{Gastroesophageal reflux}

The presence of anti-reflux barriers and luminal clearance are important factors for the prevention of injury to esophageal mucosa. Therefore, compromise of the integrity of the lower esophageal sphincter mechanism or esophageal peristalsis may predispose to the development of AEN, highlighting mucosal 
damage secondary to gastric acid reflux as a relevant factor in the pathophysiology of this disease.

This hypothesis is supported by significant associations with the presence of hiatal hernia [17] or acute gastric outlet obstruction [18,19]. However, manometry and 24-h pH monitoring performed 5-7 months after an episode of AEN have documented normal esophageal peristalsis and an absence of pathological reflux in 2 patients [20,21], which suggests that, like hemodynamic instability or general debilitation, significant gastroesophageal acid reflux is not per se an essential condition for the development of AEN and supports the view that AEN is usually the result of a combination of factors and does not have a single cause.

\section{Etiology}

The etiology of AEN is usually multifactorial and there are a number of conditions reported in association with AEN, summarized in Table 2. On the one hand, multiple chronic medical comorbidities place a patient at greater risk of developing AEN by: 1) increased susceptibility to esophageal ischemia secondary to atherosclerosis; 2) a state of general debilitation leading to an overall reduction in defense and regeneration mechanisms; and 3) excessive reflux of gastric chemical secretions that damage esophageal mucosa [2]. On the other, there is usually an acute event triggering AEN by diverse mechanisms, including, among others, a decrease in esophageal perfusion caused by hemodynamic compromise, or a massive overflow of gastric secretions resulting from acute gastric outlet obstruction or local esophageal infection. Therefore, AEN is usually triggered by an acute event that occurs against a background of a chronic debilitating process (Fig. 1).

\section{Hemodynamic compromise}

AEN is often reported in patients who present with hemodynamic compromise, often requiring admission to the intensive care unit. In patients with risk factors for significant vasculopathy, hypotension may result in inadequate tissue perfusion and eventually culminates in esophageal ischemic necrosis [2].

There are several cases of AEN secondary to septic shock [22-25], where generalized vasodilation mediated by cytokines results in hemodynamic compromise and decreased perfusion pressure. Primary infection sites include skin infection [23], urinary tract infection [24], and necrotizing fasciitis [25]. Despite aggressive treatment with fluid therapy, vasoconstrictors, proton pump inhibitors and broad-spectrum empirical antibiotic therapy, the outcome for these patients is often sepsis with multiorgan failure and death $[22,23]$.

AEN may also result from cardiogenic shock secondary to acute myocardial infarction [26], stress cardiomyopathy [27] or cardiac arrest [28]. Under such circumstances, the heart is not able to maintain an effective cardiac output, resulting in hemodynamic compromise and a state of generalized
Table 2 Etiology of acute esophageal necrosis. Acute esophageal necrosis typically occurs in association with an acute event (triggers) against a background of chronic medical conditions that confer an increased risk (risk factors). Here, we present a summary of known risk factors and possible triggering events for this disease reported to date

\begin{tabular}{ll}
\hline Risk factors & \\
\hline Male sex & Immunosuppression \\
Advanced age & Coronary heart disease \\
Diabetes mellitus & Peripheral artery disease \\
Hypertension & Congestive heart failure \\
Dyslipidemia & Chronic obstructive pulmonary disease \\
Malnutrition & Chronic kidney disease \\
Alcohol abuse & Liver cirrosis \\
Malignancy & Gastroesophageal reflux disease \\
\hline
\end{tabular}

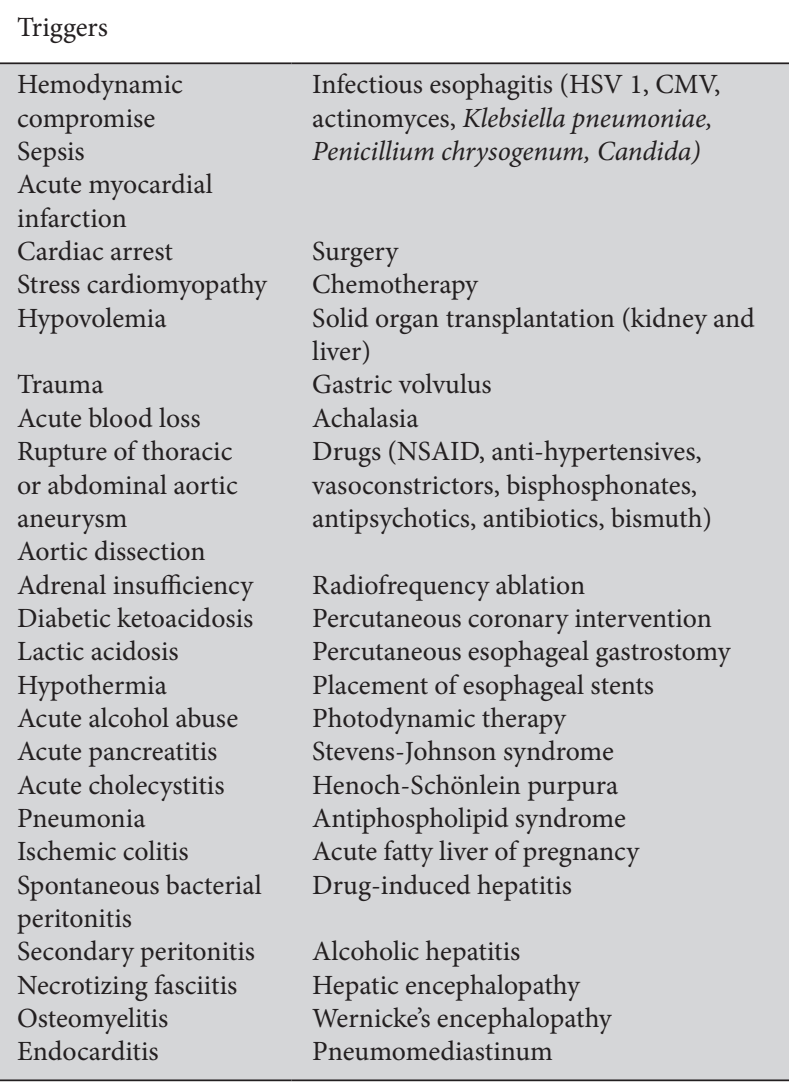

HSV, herpes simplex virus; CMV, cytomegalovirus; NSAID, nonsteroidal anti-inflammatory drugs

hypoperfusion that eventually culminates in esophageal necrosis. Like septic shock, mortality rate is high among these patients because of multiorgan failure as a result of generalized hypoperfusion [28].

Hemorrhagic shock may also result in AEN, which has been reported in association with hemodynamic compromise resulting from acute blood loss during an episode of variceal bleeding [29], rupture of a thoracic [30] or abdominal [31] aortic aneurysm, traumatic aortic transection [32] or postsurgical bleeding, for example after accidental artery laceration during orthotopic liver transplantation [33,34] or cholecystectomy [35]. 


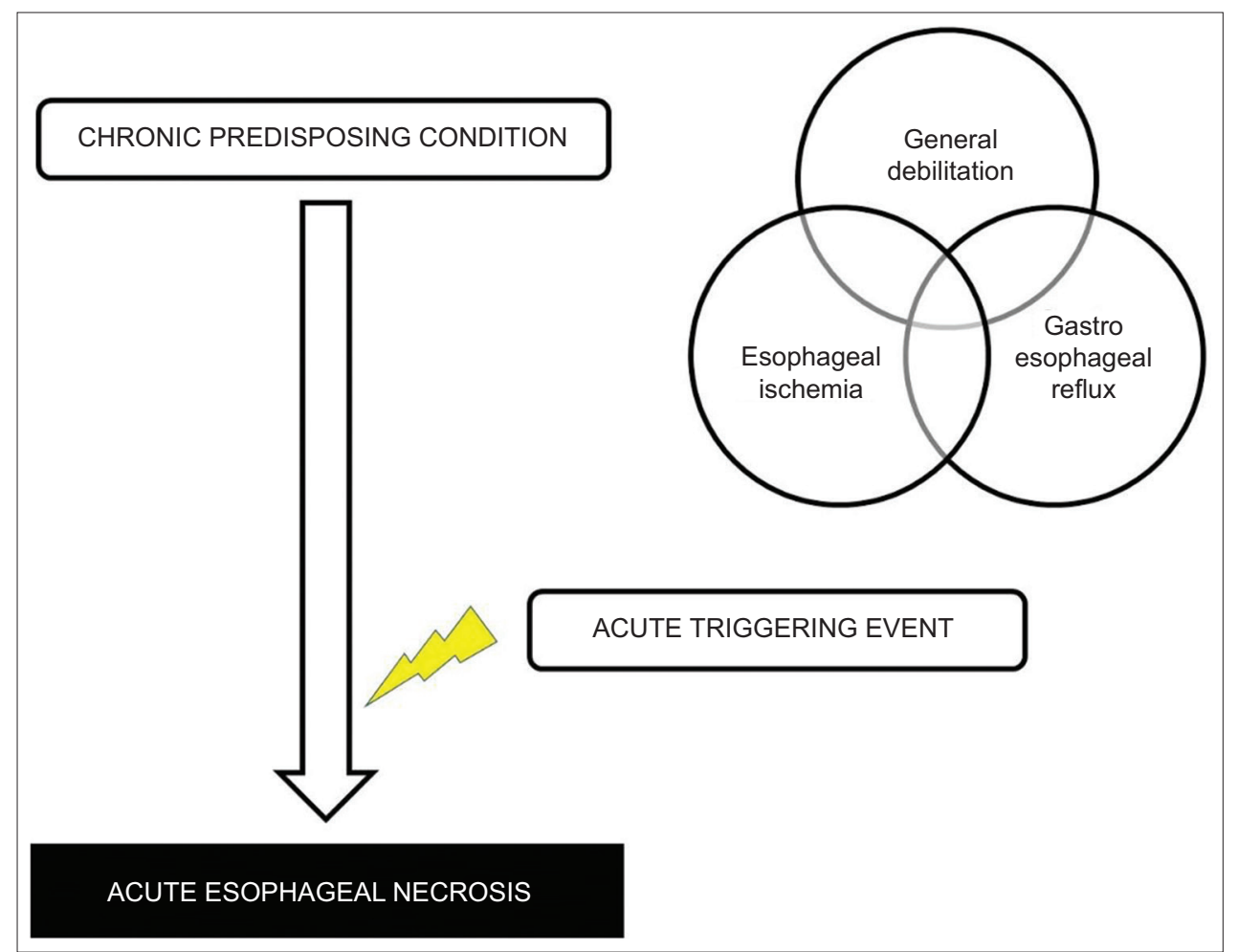

Figure 1 Pathophysiology of acute esophageal necrosis. Acute esophageal necrosis usually results from an acute triggering event that occurs against a background of chronic predisposing conditions. These processes usually involve a combination of one or more of 3 main pathophysiological mechanisms: 1) esophageal ischemia secondary to the presence of risk factors for advanced vasculopathy; 2) gastroesophageal reflux resulting in direct mucosal damage; and 3) general debilitation states resulting in impaired defense mechanisms and regenerative ability

Other causes of hemodynamic compromise resulting in AEN include excessive doses of antihypertensive drugs, especially with a combination of different classes [36], hypovolemic shock secondary to diarrhea and vomiting [37,38], or adrenal insufficiency [39]. AEN may also develop following trauma caused by falls or vehicle accidents. Patients are usually hypotensive and present with one or more bone fractures, a particular association with femur fractures being noted [40-44]. Other conditions associated with hypotension resulting in AEN include hypothermia $[45,46]$, alcoholic lactic acidosis [47], and diabetic ketoacidosis (DKA) [48,49].

\section{DKA}

DKA is one of the most common triggering events for AEN [10,25,44,48-53], with several pathogenic mechanisms that may possibly be implicated. The presence of long-standing diabetes mellitus predisposes the patient to the development of atherosclerosis and an increased risk of ischemia. Gastric stasis, which can occur in the absence of neuropathy during DKA, can induce massive gastroesophageal reflux that contributes to AEN. DKA can also result in profound osmotic diuresis, fluid loss, and hypoperfusion of the distal esophagus [52]. A recent case report found the simultaneous presence of AEN and gastric Wischnewsky spots [53], suggesting that splanchnic vasoconstriction may also play a role, in a similar way to hypothermia.

In a retrospective analysis of 16 cases of black esophagus, 4 were associated with DKA [10]. Therefore, it is vital to consider this diagnosis in patients who present with DKA and symptoms of UGB [48] — or even in their absence, as there is one report of AEN in a patient with DKA who complained only of dysphagia and had neither hematemesis nor melena [51].

\section{Hypothermia}

An association between AEN and hypothermia has been reported $[22,45,46]$. Esophageal necrosis may be secondary to a combination of low cardiac output and profound vasoconstriction caused by low body temperature, especially in the splanchnic region, resulting in esophageal ischemia [46]. The outcome is dependent on the cause of hypothermia and the patient's general state of health. Whereas a middle-aged female with no significant morbidity who presented with AEN associated with hypothermia secondary to acute alcohol intoxication evolved favorably [45], 2 other patients with multiple comorbidities found in a state of coma and hemodynamic compromise would eventually die $[22,46]$. 


\section{Inflammation}

AEN can be triggered by inflammatory/infectious conditions, including acute pancreatitis [54,55], acute cholecystitis [1], pneumonia [56,57], ischemic colitis [58], spontaneous bacterial peritonitis [57], secondary peritonitis [59], femur osteomyelitis [60], necrotizing fasciitis $[25,61]$ or endocarditis 61], possibly related to the hemodynamic effects of inflammation, where third spacing of fluids and systemic vasodilatation subsequent to the release of inflammatory mediators may result in a state of low perfusion pressure, leading to esophageal ischemic necrosis.

This hemodynamic state maybe aggravated by the presence of disseminated infection, since there are cases of AEN associated with positive blood cultures, including bacteremia from Escherichia coli [24,62], Klebsiella oxytoca [62], Staphylococcus aureus [60], or fungemia from Candida glabrata [8].

\section{Local infection}

AEN may be associated with local infection of the esophagus, with reported pathogens including herpes simplex virus 1 [63,64], cytomegalovirus [65-67], Klebsiella pneumoniae [68], Actinomyces [69], Penicillium chrysogenum [70] and Candida [71]. These may be the result of the external spread of contiguous infectious processes [68], or opportunistic primary esophageal intraluminal infections in immunocompromised patients $[65-67,70]$. Therefore, although not required to establish diagnosis, tissue biopsy is essential to identify local infection and provide proper management with directed antimicrobial therapy.

\section{Malnutrition}

AEN classically occurs in cachectic patients with poor nutritional status arising from the presence of multiple chronic medical comorbidities, including malignancy, alcohol abuse, cirrhosis, chronickidney failure, chroniclung disease, congestive heart failure, or chronic pancreatitis [22,29,55,56,72]. The presence of these critical illnesses, resulting in malnutrition, is likely to decrease esophageal mucosal defenses and impair regenerative ability. This is therefore an important cofactor in the development of AEN and these patients are at increased risk for this disease, especially if there is an acute precipitating event [3].

\section{Malignancy}

A history of malignancy is present in $10 \%$ of patients who present with AEN [11]. Reported malignancies include esophageal squamous carcinoma [73], colorectal adenocarcinoma [72], pancreatic adenocarcinoma [8], cholangiocarcinoma [74], oral cavity squamous cancer [75], pharynx squamous cancer [64], renal cell carcinoma [58], lung squamous carcinoma [76], or non-small cell lung cancer [77]. It is likely that the presence of malignancy is associated with cachexia and immune dysregulation, thereby decreasing mucosal regenerative ability and increasing susceptibility to necrosis when the patient is exposed to an acute event. In fact, in these patients, AEN often follows therapeutic interventions, including surgery [72,76] or chemotherapy [64,77]. Nevertheless, malignancy may be associated with AEN in the absence of an identified trigger [74] and, occasionally, the disease may be found in an asymptomatic patient [75].

\section{Alcohol abuse}

A previous history of chronic alcohol abuse is an important predisposing condition, being present in $25 \%$ of patients who present with AEN [11]. It may be related to a combination of poor nutritional status, reduced lower esophageal sphincter pressure and increased volume of gastric secretions [78]. Some patients presenting with AEN who have a history of chronic alcoholism also have chronic liver disease, including cirrhosis $[22,34,46,47,79,80]$, a known risk factor for AEN, or earlier hepatic changes, including milder forms of liver disease fibrosis $[12,20]$ or steatosis $[55,56]$. In addition, AEN may be triggered by acute alcohol abuse $[16,20,45,47]$, perhaps as a result of severe vomiting causing damage to esophageal mucosa [16], or low systemic pressure associated with hypothermia [45] or alcoholic lactic acidosis [47]. Binge drinking may result in AEN even in young, otherwise healthy patients [16].

\section{Surgery}

Surgery is a common trigger for AEN, perhaps related to a cytokine environment that could compromise mucosal regenerative ability and increase susceptibility to esophageal ischemia secondary to blood loss and hypotensive insults following aggressive surgical procedures, including lower limb amputation [61], total hip arthroplasty [81], cholecystectomy [1,35], rectosigmoid resection [21,72], or pulmonary lobectomy [76]. Occasionally, AEN may also follow less invasive procedures, including ocular surgery for vitreous hemorrhage [82]. Therefore, when symptoms of UGB appear during the postoperative course, especially associated with hypotension, AEN must be considered.

AEN following lung cancer surgery consisting of pulmonary lobectomy plus paraesophageal lymph node dissection could be due to impaired microcirculation flow. Therefore, it is important not to damage the arterial branches from the descending aorta to the esophagus during paraesophageal lymph node dissection [76].

\section{Solid organ transplantation}

AEN may follow kidney transplantation $[8,65,66,83]$. AEN has been reported in association with graft-versus-host disease 
approximately 3 months after renal transplantation [8] or with opportunistic local esophageal infection by cytomegalovirus during the first weeks following the procedure $[65,66]$. It has also occurred in the immediate post-transplant period, in the context of acute pulmonary edema followed by cardiac arrest [83]. There are also cases of AEN associated with orthotopic liver transplantation, either in the immediate postoperative period, secondary to hemorrhagic shock caused by inadvertent laceration of the phrenic artery $[33,34]$, or some days later in association with hypotensive ischemic insult [84].

\section{Acute gastric outlet obstruction}

There are several cases of AEN in association with conditions that result in acute gastric outlet obstruction, as a consequence of the accumulation of large volumes of gastric acid and pepsin that bathe the esophagus for prolonged periods of time, overwhelming its normal defense mechanisms and eventually resulting in esophageal necrosis [19,41]. One of these conditions that result in transient gastric outlet obstruction is gastric volvulus, which may culminate in AEN. In fact, there are cases of gastric volvulus secondary to large hiatal hernias [19], a slipped laparoscopic adjustable gastric band [85] or gastrostomy tube balloon migration into the duodenum [86], culminating in AEN. Uneventful recovery of esophageal mucosa usually follows correction of gastric volvulus [85].

The presence of large duodenal ulcers has also been implicated in AEN, secondary to marked edema and a deformed pylorus or duodenal bulb, resulting in transient gastric outlet obstruction [41]. There has also been one report of AEN secondary to migration of a surgically placed gastrostomy draining tube directly into the duodenal bulb, resulting in obstruction of the gastric outflow tract [41].

\section{Other motor and structural abnormalities}

Esophageal damage resulting from prolonged contact with gastric chemical contents may result from excessive reflux in patients with gastroesophageal reflux disease, which affects a significant proportion of patients who present with AEN [22]. Hiatal hernia is also often found in patients who present with AEN [17-19], probably related to chronic reflux and increased propensity to gastric volvulus. Another motor abnormality reported in association with AEN is achalasia [8,87], which, similarly to gastroesophageal reflux disease, results in prolonged contact between esophageal mucosa and retained food residues; over time, these ferment and become injurious to the mucosa.

\section{Drugs}

Several drugs have also been implicated in the pathogenesis of AEN, including non-steroidal anti-inflammatory drugs (NSAID) [10], antihypertensive agents [36], bismuth subsalicylate [88], terlipressin [79], cocaine [89], cefazolin [60], alendronate [90], haloperidol [91], clozapine [62,92], olanzapine [92], and afatinib [77]. The association between these drugs and black esophagus may be related to several mechanisms. Esophageal ischemia may be secondary to vasoconstriction induced by vasoconstrictive agents such as terlipressin [79], or cocaine abuse [89], or to a transient low-flow state associated with a combination of antihypertensive drugs [36]. Other drugs, including NSAID [10] or bisphosphonates [90], may induce direct esophageal damage. Although they are used in the treatment of gastroesophageal reflux disease, a chemical reaction between bismuth and sulfur molecules present in food may also damage esophageal mucosa [88].

\section{Others}

Esophageal hypoperfusion may result from other mechanisms besides vessel atherosclerosis. There is one report of AEN secondary to type B aortic dissection, where extensive thrombosis in the false lumen occludes blood flow to the intercostal arteries, leading to esophageal ischemia [14]. There was also one case of AEN resulting from esophageal ischemia induced by calcific uremic arteriolopathy [93], which could contribute to the increased risk among patients with chronic kidney disease.

Occasionally, AEN mayalso follow percutaneous procedures, including radiofrequency ablation for atrial fibrillation [34] or percutaneous coronary intervention [94]. AEN may also be associated with certain endoscopic procedures, including percutaneous esophageal gastrostomy [95], insertion of biodegradable esophageal stents [96] or photodynamic therapy for esophageal carcinoma [73].

Other conditions reported in association with AEN include Stevens-- syndrome [97], Henoch-Schönlein purpura [98], antiphospholipid syndrome [99,100], acute fatty liver of pregnancy [101], drug-induced hepatitis [102], alcoholic hepatitis [103], hepatic encephalopathy [80], Wernicke's encephalopathy [104], and pneumomediastinum [105].

\section{Clinical features and diagnosis}

AEN is a rare syndrome classically characterized by a striking endoscopic image of diffuse and circumferential black mucosal discoloration of distal esophagus with an abrupt transition at the GEJ and variable proximal extension. Patients are typically older males with multiple medical comorbidities. The clinical presentation is remarkable for UGB, with most patients presenting with hematemesis or melena. Other symptoms may include abdominal pain, nausea, vomiting, dysphagia, fever, and syncope. Physical findings may be notable for cachexia and signs of hemodynamic instability, including hypotension, and tachycardia. Associated laboratory abnormalities may include anemia (secondary to blood loss), leukocytosis (reflecting 
inflammation caused by necrosis of esophageal mucosa), and hyperlactatemia (a marker of tissue hypoperfusion) [2].

Classic AEN presents as a diffuse black-appearing esophageal mucosa that preferentially affects the distal esophagus and stops abruptly at the GEJ [2]. Proximal extension of mucosal injury is common and, in approximately $34 \%$ of cases, the entire esophagus may appear black [11]. This characteristic endoscopic appearance is sufficient to establish the diagnosis. Additional endoscopic findings may include signs of bleeding (active oozing from distal esophagus [106], blood clots [26] and/or "coffee ground" material in the stomach [85], multiple esophageal ulcerations [106], gastric ulcers [37], duodenal pathology (ulcers, erosions or edema) [39], or gastric outlet obstruction due to gastric volvulus [19].

Biopsy is supportive but is not required to establish the diagnosis. Histopathology, if performed, demonstrates an absence of viable epithelium and extensive mucosal necrosis, possibly extending into deeper layers, often associated with vascular thrombosis and severe inflammatory changes [2,107]. Although not essential to establish diagnosis, biopsy is recommended whenever possible for exclusion of local infection and other causes of black esophageal mucosa, including malignant melanoma [108], acanthosis nigricans [109], coal dust exposure [110], pseudomelanosis [111], or melanosis [112]. Biopsy specimens should be sent for bacterial, fungal and viral cultures to exclude infectious etiologies or a superimposed infection. Certain histopathologic aspects, such as multinucleated giant cells and inclusion bodies, are indicative of a viral etiology, including herpes simplex and cytomegalovirus, especially in immunocompromised patients. Immunostaining differentiates specifically herpes simplex and cytomegalovirus [65] and is therefore recommended in the presence of characteristic histopathologic findings.

Generally, uncomplicated AEN follows a predictable endoscopic trajectory, where the classic picture of diffuse black distal esophageal mucosa is followed by a healing phase dominated by residual black areas and thick white exudates composed of necrotic debris that cover pink friable mucosa [41]. Usually, esophageal mucosa acquires its normal endoscopic appearance in approximately 1-2 weeks, although, depending on the patient's general condition, this process may take more time [2]. Relapse after complete recovery is not typical, although it has been documented [82]. There is also one case of isolated duodenal necrosis 4 months after an episode of AEN [113].

Possible complications of AEN include perforation, stenosis and peristalsis abnormalities. Perforation is a dangerous complication, with a reported incidence of approximately $5 \%$ [11] that should be suspected in rapidly decompensating patients. It may lead to mediastinitis, mediastinal abscess formation and generalized sepsis, being associated with an ominous prognosis. Prompt recognition, intravenous antibiotics and surgical intervention can be life-saving. Another possible sequela of AEN is the development of strictures, which can be seen in approximately $10 \%$ of patients during follow up EGD [11] and result in significant dysphagia. Strictures probably result from excessive deposition of connective tissue during the healing phase of AEN [2]. Motor abnormalities involving peristalsis of the middle and lower thirds of esophagus have also been discovered in association with stenosis during manometry performed 3 months after the event [45].

\section{Management}

There is no specific therapy for AEN. The mainstay of therapy consists in correction of the precipitating conditions and supportive care. Systemic resuscitation with intravenous fluid therapy is recommended, even in hemodynamically stable patients, in order to optimize vascular perfusion and minimize damage secondary to ischemia. Another important measure is the administration of antacid therapy to protect esophageal mucosa from aggressive acid reflux, an important factor implicated in the pathogenesis of AEN. Aggressive intravenous proton pump inhibitor therapy should be administered until there is an improvement in clinical status, at which time a change to an oral formulation is appropriate; this should be continued for a few months after symptoms have resolved. Administration of packed red blood cell transfusions to maintain hemoglobin levels above minimal appropriate levels for the patient is also recommended. Nasogastric intubation should be avoided because it may result in esophageal perforation [61].

Prophylactic antibiotics are not necessary. Empirical broad-spectrum antibiotic therapy should be initiated in cases of fever, rapid clinical decompensation, suspected esophageal perforation or immune compromise (associated with certain clinical scenarios often reported in association with AEN, including transplant recipients, cirrhosis or chronic kidney disease). Directed antimicrobial therapy, including antibacterial, antifungal or antiviral agents, is recommended in the setting of positive esophageal cultures, stains for fungal agents or visualization of multinucleated giant cells or inclusion bodies on histological evaluation of the biopsy specimen [2].

Adequate nutrition is essential to ensure effective healing of esophageal mucosa. Bowel rest must be instituted immediately after diagnosis and the patient must be given parenteral nutrition. Enteral feeding is not recommended because of the risk of perforation. In most cases, oral feeding can be resumed some days later. If the patient does not tolerate oral feeding, total parenteral nutrition has been successfully used to maintain nutritional status until complete healing of esophageal mucosa and the resolution of dysphagia [37].

Active esophageal bleeding, if present, can be controlled with submucosal adrenaline injection [36,61]. Endoscopic placement of a self-expandable metallic covered stent is another effective strategy for achieving hemostasis [114]. Balloon tamponade with a Sengstaken-Blakemore tube should be avoided, because it has been associated with perforation [115].

Surgery is reserved for perforation resulting in mediastinitis or abscess formation, and usually consists of emergent esophagectomy followed by elective reconstruction using gastric or enteric tube $[96,115,116]$. However, placement 


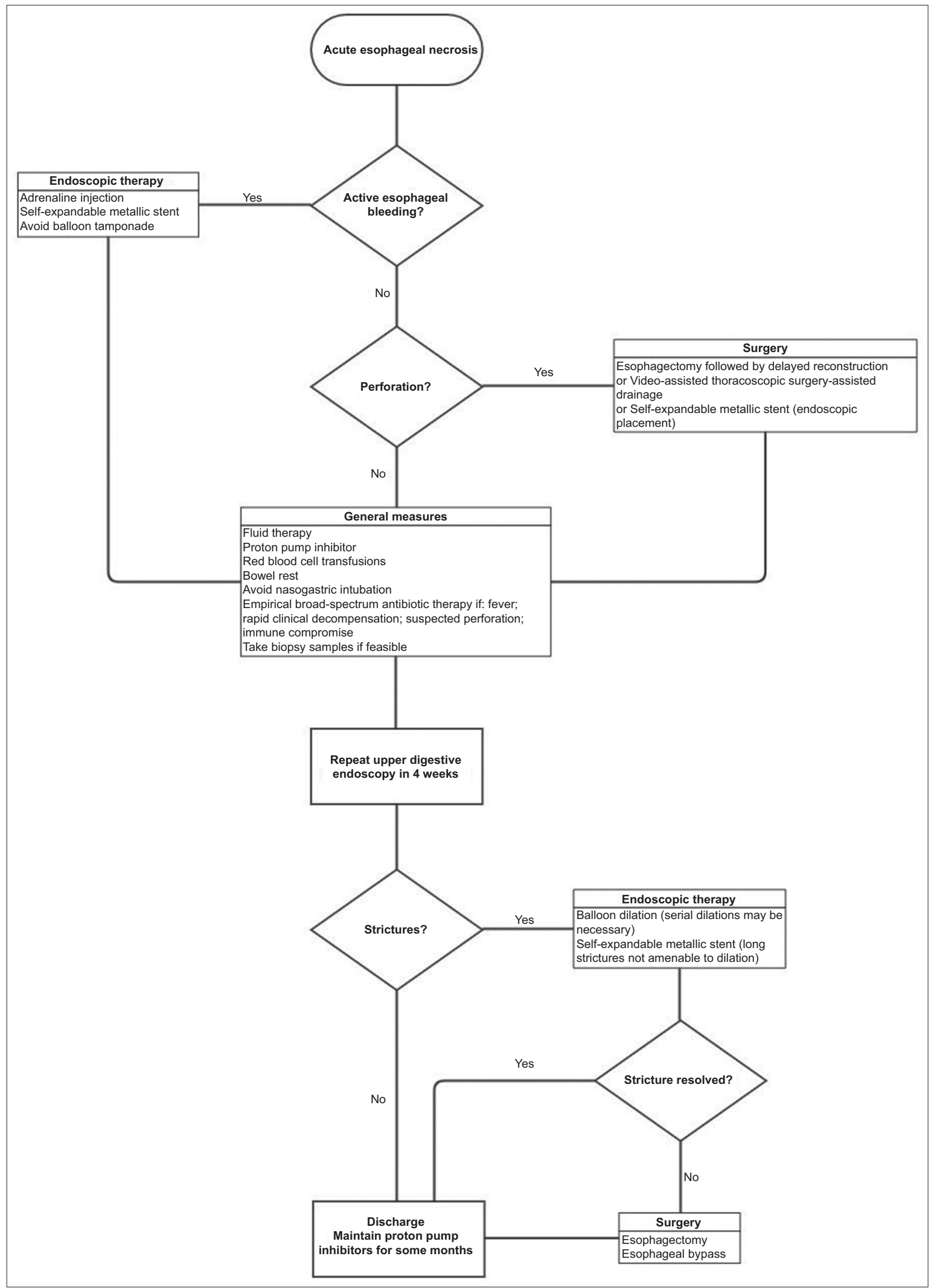

Figure 2 Simplified algorithm for management of acute esophageal necrosis and its complications 
of a fully covered self-expandable metallic stent [117] or video-assisted thoracoscopic surgery to place an intrathoracic flushing-system-drain near the perforation [118] have also been performed with success.

Repeat endoscopy is warranted to document recovery of esophageal mucosa and possible sequelae, including strictures, which may develop in $10 \%$ of cases [11]. Since recovery of esophageal mucosa usually takes place over a period of less than a month, we suggest that an adequate timing for repeat endoscopy would be approximately 1 month after initial presentation, or earlier if the patient develops symptoms of dysphagia or chest pain.

Endoscopic balloon dilation is effective as first-line treatment for strictures. However, many patients will eventually require serial endoscopies with long-term balloon dilation programs [61]. If repeated dilation is not effective, surgery is recommended; it usually consists of esophagectomy [49] and esophageal bypass [25]. For long strictures where standard dilation is not amenable, placement of a self-expandable metallic stent has been performed with success [33]. A simplified algorithm for the management of AEN and its complications is provided in Fig. 2.

\section{Prognosis}

Prognosis is poor and largely depends on the severity of the esophageal disease and the patient's general state of health. AEN is associated with a high mortality rate of approximately $32 \%$ [11], and there are even cases resulting in sudden death $[38,119,120]$, though the cause is likely to be the underlying critical illness rather than AEN. Mortality specific to AEN is approximately $6 \%$ [3].

General debilitation associated with the presence of multiple comorbidities and esophageal perforation are poor prognostic markers. Patients whose general condition is otherwise good are more likely to recover completely [20]. However, it is important to emphasize that, although AEN is a serious lifethreatening condition, appropriate treatment may result in a favorable outcome in over $60 \%$ of patients [11].

\section{Concluding remarks}

AEN is a rare cause of UGB that should be suspected in older patients with general debilitation and multiple medical conditions. Diagnosis is established by the presence of a striking endoscopic image of black distal esophagus with an abrupt transition at the GEJ and variable proximal extension. The pathophysiology of AEN is related to a combination of esophageal ischemia, general debilitation and gastroesophageal reflux. Its etiology is multifactorial, with a myriad of conditions being associated with this disease, but it is usually the result of an acute triggering event with a background of multiple chronic debilitating conditions that place a patient at higher risk. Despite its rarity, AEN is in itself a poor prognostic factor, and increased awareness of this pathology might lead to early recognition and timely institution of proper management, thereby increasing chances of survival.

We hope this review may inspire future studies that can provide further insight into AEN. Given that its pathophysiology is still largely unknown, we suggest that future directions for research in this field could focus on obtaining samples for the microscopic and molecular characterization of affected esophageal tissue. Perhaps this may provide some clues to the specific pathways involved in its pathophysiology, which could be useful for development of more specific management strategies.

\section{References}

1. Goldenberg SP, Wain SL, Marignani P. Acute necrotizing esophagitis. Gastroenterology 1990;98:493-496.

2. Gurvits GE. Black esophagus: acute esophageal necrosis syndrome. World J Gastroenterol 2010;16:3219-3225.

3. Gurvits GE, Shapsis A, Lau N, Gualtieri N, Robilotti JG. Acute esophageal necrosis: a rare syndrome. $J$ Gastroenterol 2007;42:29-38.

4. Moretó M, Ojembarrena E, Zaballa M, Tánago JG, Ibánez S. Idiopathic acute esophageal necrosis: not necessarily a terminal event. Endoscopy 1993;25:534-538.

5. Augusto F, Fernandes V, Cremers MI, et al. Acute necrotizing esophagitis: a large retrospective case series. Endoscopy 2004;36:411-415

6. Julián Gómez L, Barrio J, Atienza R, et al. [Acute esophageal necrosis. An underdiagnosed disease]. Rev Esp Enferm Dig 2008;100:701-705.

7. Ramos R, Mascarenhas J, Duarte P, Vicente C, Casteleiro C. [Acute esophageal necrosis: a retrospective case series]. Rev Esp Enferm Dig 2008;100:583-585.

8. Singh D, Singh R, Laya AS. Acute esophageal necrosis: a case series of five patients presenting with "Black esophagus". Indian J Gastroenterol 2011;30:41-45.

9. Ben Soussan E, Savoye G, Hochain P, et al. Acute esophageal necrosis: a 1-year prospective study. Gastrointest Endosc 2002;56:213-217.

10. Yasuda H, Yamada M, Endo Y, Inoue K, Yoshiba M. Acute necrotizing esophagitis: role of nonsteroidal anti-inflammatory drugs. J Gastroenterol 2006;41:193-197.

11. Abdullah HM, Ullah W, Abdallah M, Khan U, Hurairah A, Atiq M. Clinical presentations, management, and outcomes of acute esophageal necrosis: a systemic review. Expert Rev Gastroenterol Hepatol 2019;13:507-514.

12. Cameron PA, Schweiger F. Forsaken Foregut: Case report of simultaneous black esophagus and ischemic cholangiopathy. Case Rep Med 2017;2017:8362613.

13. Gargot D, Causse X, Sapey T, et al. [Black esophagus: a new case associated with hypoxic hepatitis]. Gastroenterol Clin Biol 1994;18:177-179.

14. van de Wal-Visscher E, Nieuwenhuijzen GA, van Sambeek MR, et al. Type B aortic dissection resulting in acute esophageal necrosis. Ann Vasc Surg 2011;25:837.e1-e3.

15. Katsinelos P, Christodoulou K, Pilpilidis I, et al. Black esophagus: an unusual finding during routine endoscopy. Endoscopy 2001;33:904.

16. Katsinelos P, Pilpilidis I, Dimiropoulos S, et al. Black esophagus induced by severe vomiting in a healthy young man. Surg Endosc 2003; 17:521. 
17. McLaughlin CW, Person TD, Denlinger CE. Management of acute esophageal necrosis syndrome. J Thorac Cardiovasc Surg 2011;141:e23-e24.

18. Nunes G, Patita M, Fernandes V, Fonseca J. Paraesophageal hernia and gastric volvulus: an uncommon etiology of vomiting and upper gastrointestinal bleeding. Rev Esp Enferm Dig 2017;109:294-295.

19. Kram M, Gorenstein L, Eisen D, Cohen D. Acute esophageal necrosis associated with gastric volvulus. Gastrointest Endosc 2000;51:610-612.

20. Yamauchi J, Mitsufuji S, Taniguchi J, et al. Acute esophageal necrosis followed by upper endoscopy and esophageal manometry/pH test. Dig Dis Sci 2005;50:1718-1721.

21. Reichart M, Busch OR, Bruno MJ, Van Lanschot JJ. Black esophagus: a view in the dark. Dis Esophagus 2000;13:311-313.

22. Kalva NR, Tokala MR, Dhillon S, et al. An unusual cause of acute upper gastrointestinal bleeding: acute esophageal necrosis. Case Rep Gastrointest Med 2016;2016:6584363.

23. Lahbabi M, Ibrahimi A, Aqodad N. Acute esophageal necrosis: a case report and review. Pan Afr Med J 2013;14:109.

24. Wallberg ME, Young P, Finn BC, Thomé M, Chueco AA, Villarejo F. [Black esophagus due to acute necrotizing esophagitis: report of one case]. Rev Med Chil 2009;137:672-674.

25. Sakatoku Y, Fukaya M, Miyata K, Nagino M. Successful bypass operation for esophageal obstruction after acute esophageal necrosis: a case report. Surg Case Rep 2017;3:4.

26. Neumann DA $2^{\text {nd }}$, Francis DL, Baron TH. Proximal black esophagus: a case report and review of the literature. Gastrointest Endosc 2009;70:180-181.

27. Muller-Engelmann J, Paparoupa M, Nierhaus A, et al. Necrotizing esophagitis by stress-cardiomyopathy with right ventricular insufficiency. Med Klin Intensivmed Notfmed 2018 Dec 10 [Epub ahead of print]. doi: 10.1007/s00063-018-0517-8

28. Shah A, Thoguluva Chandreskar V, Doobay R, Kahlon A, Amzuta I. Acute esophageal necrosis in an alcoholic after successful resuscitation from cardiac arrest. Case Rep Gastrointest Med 2017;2017:5092906.

29. Maroy B. Black esophagus complicating variceal bleeding. Endoscopy 2013;45 Suppl 2 UCTN: E237.

30. Watanabe S, Nagashima R, Shimazaki Y, et al. Esophageal necrosis and bleeding gastric ulcer secondary to ruptured thoracic aortic aneurysm. Gastrointest Endosc 1999;50:847-849.

31. Rodrigo M, Gorráiz BE, Merino C, Eguaras J, Elizalde JM, Soler W. [Acute necrotizing esophagitis in an unstable patient]. An Sist Sanit Navar 2009;32:113-116.

32. Park NH, Kim JH, Choi DY, et al. Ischemic esophageal necrosis secondary to traumatic aortic transection. Ann Thorac Surg 2004;78:2175-2178.

33. Gómez V, Propst JA, Francis DL, Canabal JM, Franco PM. Black esophagus: an unexpected complication in an orthotopic liver transplant patient with hemorrhagic shock. Dig Dis Sci 2014;59:2597-2599.

34. Kim DB, Bowers S, Thomas M. Black and white esophagus: rare presentations of severe esophageal ischemia. Semin Thorac Cardiovasc Surg 2017;29:256-259.

35. Loghmari MH, Ben Mansour W, Guediche A, Bouhlel W, Gahbiche M, Safer L. Black esophagus: a case report. Tunis Med 2018;96:142-147.

36. Burtally A, Gregoire P. Acute esophageal necrosis and low-flow state. Can J Gastroenterol 2007;21:245-247.

37. Brar TS, Helton R, Zaidi Z. Total parenteral nutrition successfully treating black esophagus secondary to hypovolemic shock. Case Rep Gastrointest Med 2017;2017:4396870.

38. Unuma K, Harada K, Funakoshi T, Uemura K. Sudden death of an alcoholic elderly man with acute esophageal necrosis (black esophagus). Forensic Sci Int 2011;212:e15-e17.
39. Koop A, Bartel MJ, Francis D. A case of acute esophageal necrosis and duodenal disease in a patient with adrenal insufficiency. Clin Gastroenterol Hepatol 2016;14:A17-A18.

40. Kabaçam G, Yakut M, Soykan I. Acute esophageal necrosis: a rare cause of gastrointestinal bleeding. Dig Endosc 2012;24:283.

41. Lacy BE, Toor A, Bensen SP, Rothstein RI, Maheshwari Y. Acute esophageal necrosis: report of two cases and a review of the literature. Gastrointest Endosc 1999;49:527-532.

42. Albuquerque A, Ramalho R, Rios E, Lopes JM, Macedo G. Black esophagus. Dis Esophagus 2013;26:333.

43. Fernández Carrillo C, Barrios Peinado C, Pons Renedo F. Acute necrotizing esophagitis in a patient with femur fracture. Rev Esp Enferm Dig 2011;103:436-437.

44. Casella G, Perego D, Corti G, et al. Black esophagus: should it be considered an unfavorable prognostic factor? Dis Esophagus 2001;14:166-168.

45. Cadot $\mathrm{P}$, Duverger V, Imperato $M$, Lapprand $M$, Vergos $M$. [Black esophagus associated with hypothermia]. Ann Chir 2001;126:903-905.

46. Živković V, Nikolić S. The unusual appearance of black esophagus in a case of fatal hypothermia: a possible underlying mechanism. Forensic Sci Med Pathol 2013;9:613-614.

47. Endo T, Sakamoto J, Sato K, et al. Acute esophageal necrosis caused by alcohol abuse. World J Gastroenterol 2005;11:5568-5570.

48. Talebi-Bakhshayesh M, Samiee-Rad F, Zohrenia H, Zargar A. Acute esophageal necrosis: a case of black esophagus with DKA. Arch Iran Med 2015;18:384-385.

49. Kim YH, Choi SY. Black esophagus with concomitant candidiasis developed after diabetic ketoacidosis. World J Gastroenterol 2007; 13:5662-5663.

50. Shimamura Y, Nakamura K, Ego M, Omata F. Advanced endoscopic imaging in black esophagus. Can J Gastroenterol Hepatol 2014;28:471-472.

51. Rigolon R, Fossà I, Rodella L, Targher G. Black esophagus syndrome associated with diabetic ketoacidosis. World J Clin Cases 2016;4:56-59.

52. Field Z, Kropf J, Lytle M, Castaneira G, Madruga M, Carlan SJ. Black esophagus: a rare case of acute esophageal necrosis induced by diabetic ketoacidosis in a young adult female. Case Rep Gastrointest Med 2018;2018:7363406.

53. McCarthy S, Garland J, Hensby-Bennett S, et al. Black esophagus (acute necrotizing esophagitis) and wischnewsky lesions in a death from diabetic ketoacidosis: a possible underlying mechanism. Am J Forensic Med Pathol 2019 Jan 23 [Epub ahead of print]. doi: 10.1097/PAF.0000000000000463

54. de la Serna-Higuera C, Martínez J, Martín-Arribas MI, Rodríquez-Gómez S, Pérez-Villoria A, Betancourt A. Acute necrotizing esophagitis. Gastrointest Endosc 2001;54:225.

55. Averbukh LD, Mavilia MG, Gurvits GE. Acute esophageal necrosis: a case series. Obes Surg 2018;10:e2391.

56. Galtés I, Gallego M, Esgueva R, Martin-Fumadó C. Acute oesophageal necrosis (black oesophagus). Rev Esp Enferm Dig 2016;108:154-155.

57. Gurvits GE, Cherian K, Shami MN, et al. Black esophagus: new insights and multicenter international experience in 2014. Dig Dis Sci 2015;60:444-453.

58. Tsao C, Thomas L, McGoey RR. Pathology image of the month. Black esophagus detected at autopsy in a patient with abdominal pain and bloody diarrhea. DIAGNOSIS: Acute esophageal necrosis, ischemic and pseudomembranous colitis. J La State Med Soc 2014; 166:188-190.

59. Matsumoto N, Oki E, Morita M, et al. Successful treatment of acute esophageal necrosis caused by intrathoracic gastric volvulus: report of a case. Surg Today 2009;39:1068-1072.

60. Barnes T, Yan S, Kaakeh Y. Necrotizing Esophagitis and Bleeding Associated With Cefazolin. Ann Pharmacother 
2014;48:1214-1218.

61. Shafa S, Sharma N, Keshishian J, Dellon ES. The black esophagus: a rare but deadly disease. ACG Case Rep J 2016;3:88-91.

62. Osterman MT, Foley C, Matthias I. Clozapine-induced acute gastrointestinal necrosis: a case report. J Med Case Rep 2017;11:270

63. Nagri S, Hwang R, Anand S, Kurz J. Herpes simplex esophagitis presenting as acute necrotizing esophagitis ("black esophagus") in an immunocompetent patient. Endoscopy 2007;39(Suppl 1):E169.

64. Cattan P, Cuillerier E, Cellier C, et al. Black esophagus associated with herpes esophagitis. Gastrointest Endosc 1999;49:105-107.

65. Trappe R, Pohl H, Forberger A, Schindler R, Reinke P. Acute esophageal necrosis (black esophagus) in the renal transplant recipient: manifestation of primary cytomegalovirus infection. Transpl Infect Dis 2007;9:42-45.

66. Mena Lora A, Khine J, Khosrodad N, Yeldandi V. Unusual manifestations of acute cytomegalovirus infection in solid organ transplant hosts: a report of two cases. Case Rep Transplant 2017;2017:4916973.

67. Barjas E, Pires S, Lopes J, et al. Cytomegalovirus acute necrotizing esophagitis. Endoscopy 2001;33:735.

68. Liu YH, Lin YS, Chen HJ, Tu CY, Chen W. Klebsiella pneumoniae deep neck infection with acute necrotizing esophagitis. South Med J 2009;102:219.

69. Benítez Roldán A, López-Cepero Andrada J, Amaya Vidal A, Castro Aguilar-Tablada T, Ruiz Campos JL. [Acute necrotizing esophagitis]. Gastroenterol Hepatol 2000;23:79-81.

70. Hoffman M, Bash E, Berger SA, Burke M, Yust I. Fatal necrotizing esophagitis due to Penicillium chrysogenum in a patient with acquired immunodeficiency syndrome. Eur J Clin Microbiol Infect Dis 1992;11:1158-1160.

71. Sharma V, De A, Ahuja A, Lamoria S, Lamba BM. Acute esophageal necrosis caused by candidiasis in a patient with systemic lupus erythematosus. J Emerg Med 2016;51:77-79.

72. Rodrigues BD, Dos Santos R, da Luz MM, Chaves E Silva F, Reis IG. Acute esophageal necrosis. Clin J Gastroenterol 2016;9:341-344.

73. Mall JW, Zuckermann-Becker H, Pollmann C, Opitz I, Rogalla P, Walter M. Esophageal necrosis and perforation of the left main bronchus following photodynamic therapy of esophageal carcinoma. Thorac Cardiovasc Surg 2002;50:111-113.

74. Odelowo OO, Hassan M, Nidiry JJ, Marshalleck JJ. Acute necrotizing esophagitis: a case report. I Natl Med Assoc 2002;94:735-737.

75. Rejchrt S, Douda T, Kopácová M, et al. Acute esophageal necrosis (black esophagus): endoscopic and histopathologic appearance. Endoscopy 2004;36:1133.

76. Katsuhara K, Takano S, Yamamoto Y, Ueda S, Nobuhara K, Kiyasu Y. Acute esophageal necrosis after lung cancer surgery. Gen Thorac Cardiovasc Surg 2009;57:437-439.

77. Matsumoto Y, Kuroki S, Yamada H. Gastrointestinal: Afatinibinduced acute esophageal necrosis. J Gastroenterol Hepatol 2018 Jul 11 [Epub ahead of print]. doi: 10.1111/jgh.14308

78. Hong JW, Kim SU, Park HN, Seo JH, Lee YC, Kim H. Black esophagus associated with alcohol abuse. Gut Liver 2008;2:133-135.

79. Efthymakis K, Massacesi C, Milano A, et al. Acute esophageal necrosis: possible association with terlipressin. Endoscopy 2014;46 Suppl 1 UCTN: E279-E280.

80. Khan AM, Hundal R, Ramaswamy V, Korsten M, Dhuper S. Acute esophageal necrosis and liver pathology, a rare combination. World J Gastroenterol 2004;10:2457-2458.

81. Hermet A, Lidove O, Grimbert S, Zeller V, Ducroquet F, Ziza JM. [Black esophagus]. Rev Med Interne 2014;35:393-395.

82. Tanaka K, Toyoda H, Hamada Y, et al. A relapse case of acute necrotizing esophagitis. Endoscopy 2007;39(Suppl 1):E305.
83. Caravaca-Fontán F, Jimenez S, Fernández-Rodríguez A, Marcén R, Quereda C. Black esophagus in the early kidney posttransplant period. Clin Kidney J 2014;7:613-614.

84. Planchard JA, Dikstein AF, Koveleskie J, Cohen A, Gurvits GE. Acute esophageal necrosis following orthotopic liver transplantation. Cureus 2019;11:e4090.

85. Moore C, Matthews LR, Danner O, et al. "Black esophagus" and gastric volvulus following slipped laparoscopic adjustable gastric band. Obes Surg 2018;28:2941-2948.

86. Grudell AB, Mueller PS, Viggiano TR. Black esophagus: report of six cases and review of the literature, 1963-2003. Dis Esophagus 2006; 19:105-110.

87. Lee JK, Bhargava V, Mittal RK, Ghosh P. Achalasia, alcohol-stasis, and acute necrotizing esophagitis: connecting the dots. Dig Dis Sci 2011;56:612-614.

88. Abed J, Mankal P, Judeh H, Kim S. Acute esophageal necrosis: a case of black esophagus associated with bismuth subsalicylate ingestion. ACG Case Rep J 2014;1:131-133.

89. Ullah W, Abdullah HMA, Rauf A, Saleem K. Acute oesophageal necrosis: a rare but potentially fatal association of cocaine use. BMJ Case Rep 2018;2018.

90. Kimura Y, Seno H, Yamashita Y. A case of acute necrotizing esophagitis. Gastrointest Endosc 2014;80:525-526.

91. Hejna P, Ublová M, Voříšek V. Black esophagus: acute esophageal necrosis in fatal haloperidol intoxication. J Forensic Sci 2013;58:1367-1369.

92. Pautola L, Hakala T. Medication-induced acute esophageal necrosis: a case report. J Med Case Rep 2016;10:267.

93. Akhtar J, Gorantla VK, Snell PD, Wall BM. Acute esophageal necrosis (black esophagus) complicating calcific uremic arteriolopathy. Clin Nephrol 2019;91:48-51.

94. Kwon HJ, Park SH, Ahn JH, Lee TH, Lee CK. Acute esophageal necrosis occurring in a patient undergoing percutaneous coronary intervention. Korean J Intern Med 2014;29:379-382.

95. Carrera VG, Rodriguez SV, Gonzalez de la Ballina Gonzalez E, Luis Ulla Rocha J. Acute esophageal necrosis in a patient with multiple comorbidity. Ann Gastroenterol 2012;25:162.

96. Tse A, Basu S, Ali H, Hamouda A. Black necrotic oesophagus following the use of biodegradable stent for benign oesophageal stricture. J Surg Case Rep 2015;2015.

97. Mahé A, Kéita S, Blanc L, Bobin P. Esophageal necrosis in the Stevens-Johnson syndrome. J Am Acad Dermatol 1993;29:103-104.

98. Iorio N, Bernstein GR, Malik Z, Schey R. Acute esophageal necrosis presenting with Henoch-Schonlein purpura. ACG Case Rep J 2015;3:17-19.

99. Padda A, Mandalia A, Sawalha AH. Clinical images: Black esophagus in antiphospholipid syndrome. Arthritis Rheumatol 2017;69:1460.

100. Cappell MS. Esophageal necrosis and perforation associated with the anticardiolipin antibody syndrome. Am J Gastroenterol 1994;89:1241-1245.

101. Macedo G, Correia A, Maia J, Ribeiro T. Re: black esophagus. Am J Gastroenterol 1998;93:855-856.

102. Watermeyer GA, Shaw JM, Krige JE. Education and imaging. Gastrointestinal: acute necrotizing esophagitis. J Gastroenterol Hepatol 2007;22:1162.

103. Săftoiu A, Cazacu S, Kruse A, Georgescu C, Comănescu V, Ciurea T. Acute esophageal necrosis associated with alcoholic hepatitis: is it black or is it white? Endoscopy 2005;37:268-271.

104. Lanternier F, Somogyi A, Kahn JE, Leport J. [Acute necrotizing esophagitis and Wernicke's encephalopathy in an alcoholic/ smoker discovered during alcohol withdrawal]. Gastroenterol Clin Biol 2004;28:1299-1300.

105. Carter RR, Coughenour JP, Van Way CW $3^{\text {rd }}$, Goldstrich J. Acute esophageal necrosis with pneumomediastinum: a case 
report. Mo Med 2007;104:276-278.

106. Abu-Zaid A, Solimanie S, Abudan Z, Al-Hussaini H, Azzam A, Amin T. Acute esophageal necrosis (black esophagus) in a 40-year-old man. Ann Saudi Med 2015;35:80-81.

107. Jessurun J, Cui I, Aristi-Urista G. Acute (gangrenous) esophageal necrosis (black esophagus): A rare form of injury with specific histologic features and diverse clinical associations with a common pathogenesis. Hum Pathol 2019:87:44-50.

108. Lasota J, Kowalik A, Felisiak-Golabek A, et al. Primary malignant melanoma of esophagus: clinicopathologic characterization of 20 cases including molecular genetic profiling of 15 tumors. Mod Pathol 2019;32:957-966.

109. Kozlowski LM, Nigra TP. Esophageal acanthosis nigricans in association with adenocarcinoma from an unknown primary site. J Am Acad Dermatol 1992;26:348-351.

110. Khan HA. Coal dust deposition-rare cause of "black esophagus". Am J Gastroenterol 1996;91:2256.

111. Kimball MW. Pseudomelanosis of the esophagus. Gastrointest Endosc 1978;24:121-122.

112. Sharma SS, Venkateswaran S, Chacko A, Mathan M. Melanosis of the esophagus. An endoscopic, histochemical, and ultrastructural study. Gastroenterology 1991;100:13-16.

113. Del Hierro PM. Acute necrotizing esophagitis followed by duodenal necrosis. Gastroenterology Res 2011;4:286-288.

114. Messner Z, Gschwantler M, Resch H, Bodlaj G. Use of the Ella Danis stent in severe esophageal bleeding caused by acute necrotizing esophagitis. Endoscopy 2014;46 Suppl 1 UCTN: E225-E226.

115. Wu MH, Wu HY. Incremental change in acute esophageal necrosis: report of two cases. Surg Today 2014;44:363-365.

116. Worrell SG, Oh DS, Greene CL, DeMeester SR, Hagen JA. Acute esophageal necrosis: a case series and long-term follow-up. Ann Thorac Surg 2014;98:341-342.

117. Sato H, Ishida K, Sasaki S, et al. Regulating migration of esophageal stents - management using a Sengstaken-Blakemore tube: A case report and review of literature. World J Gastroenterol 2018;24:3192-3197.

118. Groenveld RL, Bijlsma A, Steenvoorde P, Ozdemir A. A black perforated esophagus treated with surgery: Report of a case. World J Gastrointest Surg 2013;5:199-201.

119. Venara A, Pavageau AH, Maillart CR, Jousset N. Sudden death due to black esophagus: a case report. Am J Forensic Med Pathol 2013;34:16-17.

120. Nikolić S, Zivković V. [Black esophagus-case report]. Srp Arh Celok Lek 2014;142:94-98. 